\title{
Glycaemia and hand grip strength in aging people: Guangzhou biobank cohort study
}

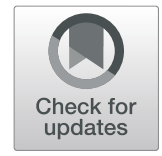

Xue Liang ${ }^{1}$, Chao Qiang Jiang ${ }^{2}$, Wei Sen Zhang ${ }^{2}$, Feng Zhu², Ya Li Jin², Kar Keung Cheng ${ }^{3}$, Tai Hing Lam ${ }^{2,4^{*}}$ and $\operatorname{Lin} X u^{1,4^{*}}$ (i)

\begin{abstract}
Background: There is a link between hyperglycemia and mechanical functions of muscle. However, existing evidence of the association between hyperglycemia and weaker muscle strength is limited and inconsistent. We examined whether glycemic status was associated with relative grip strength (RGS) in older Chinese.

Methods: In 2008-2012, 9180 participants (2516 men and 6664 women) from the Guangzhou Biobank Cohort Study had fasting and 2-h post-load glucose measured. Glycemic status was categorized as normoglycaemia, prediabetes (i.e., impaired fasting glucose and/or impaired glucose tolerance) and diabetes. RGS was assessed using a Jamar Hydraulic Hand Dynamometer divided by body mass index. General linear model was used to assess the association of glycemic status with RGS.

Results: After adjusting for age, smoking status, alcohol use, physical activity, health status, body fat percentage and waist circumference, in men, hyperglycemia was associated with a lower RGS, with the RGS being 1.38 (95\% confidence interval $(\mathrm{Cl})=1.34,1.42)$ in normoglycaemia, $1.35(95 \% \mathrm{Cl}=1.30,1.39)$ in prediabetes, $1.33(95 \% \mathrm{Cl}=1.29$, 1.38) in newly diagnosed diabetes and $1.32(95 \% \mathrm{Cl}=1.27,1.37)$ in known diabetes ( $P$ for trend $<0.001)$. The association of glycemic status with RGS was non-significant in women. Among the normoglycaemic group, no association was found between fasting glucose and RGS in men, whereas a significantly inverse association was found in women, with adjusted $\beta$ for RGS per mmol/l increase in fasting glucose being -0.05 to -0.04 ( $P$ values from 0.002 to 0.03 ).

Conclusions: Higher fasting glucose was associated with reduced grip strength in a dose-response manner, and the association was significant even in women with normoglycaemia. Our findings suggest that lowering glucose across the whole range might be important in preserving muscle strength, especially in aging women.
\end{abstract}

Keywords: Glycaemia, Prediabetes, Normoglycaemia, Grip strength

\section{Background}

Low muscle strength is an indicator for frailty [1] which is more prevalent in people with diabetes than those without [2], and predicts higher risks of disability, falls [3] and mortality [4]. Grip strength has been shown to be a good proxy for general muscle strength $[5,6]$,

\footnotetext{
* Correspondence: hrmrlth@hku.hk; xulin27@mail.sysu.edu.cn

${ }^{2}$ Guangzhou No.12 Hospital, Guangzhou 510620, China

'School of Public Health, Sun Yat-sen University, Guangzhou, China

Full list of author information is available at the end of the article
}

especially in older people [5]. Identifying modifiable factors associated with grip strength may enable effective primary and secondary prevention strategies in preserving ageing-related muscle loss.

Diabetes mellitus (DM) is a major chronic disease with severe complications. The number of DM patients has reached 463 million globally in 2019 and is estimated to increase to 700 million in 2045 [7]. China has the largest number of DM patients in the world, with more than one tenth of Chinese adults having DM in the recent

(c) The Author(s). 2020 Open Access This article is licensed under a Creative Commons Attribution 4.0 International License, which permits use, sharing, adaptation, distribution and reproduction in any medium or format, as long as you give appropriate credit to the original author(s) and the source, provide a link to the Creative Commons licence, and indicate if changes were made. The images or other third party material in this article are included in the article's Creative Commons licence, unless indicated otherwise in a credit line to the material. If material is not included in the article's Creative Commons licence and your intended use is not permitted by statutory regulation or exceeds the permitted use, you will need to obtain permission directly from the copyright holder. To view a copy of this licence, visit http://creativecommons.org/licenses/by/4.0/ The Creative Commons Public Domain Dedication waiver (http://creativecommons.org/publicdomain/zero/1.0/) applies to the data made available in this article, unless otherwise stated in a credit line to the data. 
decade $[8,9]$. Diabetes is associated with poorer physical performance and disability in older people $[10,11]$. However, there are limited data describing the risk of poor physical performance from glycemic measures, and increased risk may begin at levels below the current diagnostic criteria for prediabetes or diabetes. To our knowledge, there were only three papers with inconsistent results. One showed that type 2 diabetes mellitus (T2DM) was associated with lower grip strength in men and the association was less pronounced but still significant in women [12]. Another reported a positive association between fasting glucose and grip strength in men but not in women, and no association between 2-h post-load glucose (2hPG) and grip strength in men or women [13]. The third found that muscle strength was significantly lower in the highest versus lowest quartile of hemoglobin $A_{1 c}$ but sex differences or fasting glucose and 2hPG were not reported [14]. We therefore examined the association between glycemic status and grip strength using a large sample of middle-aged to older people from the Guangzhou Biobank Cohort Study (GBCS).

\section{Methods}

\section{Study sample}

All participants were from GBCS, which is an on-going three-way collaborative project of the Guangzhou 12th Hospital and the Universities of Hong Kong, China and Birmingham, United Kingdom. Details of GBCS have been reported elsewhere [15]. Briefly, all participants were recruited from the Guangzhou Health and Happiness Association for the Respectable Elders (GHHARE), a large social and welfare organization. Guangzhou permanent residents aged 50+ years were eligible to participate, with a monthly membership fee of $4 \mathrm{RMB}$ (about 0.57 USD). The GHHARE included about $7 \%$ of residents in this age group, with branches over all districts of Guangzhou. The study was approved by the Guangzhou Medical Ethics Committee of the Chinese Medical Association. All participants provided written informed consent before participation.

\section{Measures}

In this paper, we used data from participants who returned for the second examination during March 2008 to December 2012. Age range of the participants was from 53 to 98 years, with the mean age being 68 and 65 years for men and women, respectively. Within agegroup, it has been shown that participants had similar levels of diabetes and hypertension to the nationally representative samples of urban Chinese [15-17]. In 9195 participants, after excluding those with missing information $(n=15), 9180$ participants were included in the analyses. Face-to-face interviews [15] were conducted to collect baseline information by trained nurses including demographic characteristics, lifestyle, and personal and family medical history. Body mass index (BMI) was calculated using measured weight and height as kilograms divided by meters squared. Education was self-reported and classified into three groups: primary or below (0-6 years), middle school (7-12 years) and college or above ( $\geq 13$ years). Smoking status was defined as having smoked at least one cigarette per day or 7 cigarettes per week for at least half a year, and classified into three groups: never (those did not smoke during their life time), former (used to smoke but not smoking currently) and current (answering 'yes' to the question: 'do you smoke cigarettes now?'). Alcohol use was classified into three groups: never (those never consumed any alcoholic beverage during their life), former (those stopped drinking for more than one year) and current (those drunk any alcoholic beverage in the past 12 months). Physical activity was assessed by a validated Chinese version of the International Physical Activity Questionnaire [18] and classified into three groups: active (vigorous activity $\geq 3$ days a week achieving at least 1500 metabolic equivalent values (MET) or moderate activity $\geq 3000$ METs daily), minimally active (vigorous activity $\geq 3$ days a week achieving 480 METs or any combination of walking, moderate or vigorous activities $\geq 5$ days a week achieving 600 METs) and inactive (those did not meet the criteria for active or minimally active). As age [19], education [20, 21], lifestyle factors (smoking status, alcohol use [22] and physical activity [23]), health status and anthropometric parameters (body fat percentage [24], waist circumference [25] and BMI [26]) may be associated with both glycaemia and grip strength, these factors were considered as potential confounders and adjusted in the multivariable models.

\section{Exposures}

All participants were required to fast for at least $10 \mathrm{~h}$ from the night before blood taking in the morning. Fasting glucose were measured by Shimadzu CL-8000 Clinical Chemistry Analyzer (Shimadzu, Kyoto, Japan). Two-hour post-load glucose (2hPG) was measured after 75 -g oral glucose administration in all participants except for those with self-reported physician diagnosis of diabetes or with glucose-lowering treatment. Participants were categorized into six groups, including (1) normoglycaemia, (2) impaired fasting glucose (IFG) only, (3) impaired glucose tolerance (IGT) only, (4) IFG and IGT, (5) newly diagnosed T2DM and (6) known T2DM [27]. Although we found higher fasting glucose was associated with higher $2 \mathrm{hPG}$, of those who had prediabetes, those with IFG/IGT only had only one glycemic impairment indicating the other glycemic function was fairly normal. IFG + IGT were those had higher glycaemia in both 
fasting glucose and 2hPG, which had higher risk for T2DM than IFG/IGT only [28]. The six exposure groups were classified from normoglycaemia to prediabetes then to diabetes (Fig. 1). Normoglycaemia was defined by both fasting glucose $<5.6 \mathrm{mmol} / \mathrm{l}$ and $2 \mathrm{hPG}<7.8 \mathrm{mmol} /$ 1. According to American Diabetes Association [28], IFG only was defined by a fasting glucose level of 5.6-6.9 $\mathrm{mmol} / \mathrm{l}$ and $2 \mathrm{hPG}<7.8 \mathrm{mmol} / \mathrm{l}$. IGT only was defined by a $2 \mathrm{hPG}$ level of $7.8-11.09 \mathrm{mmol} / \mathrm{l}$ and fasting glucose $<5.6 \mathrm{mmol} / \mathrm{l}$. IFG and IGT (i.e., IFG + IGT) was defined by the presence of both impaired fasting glucose and impaired glucose tolerance (i.e., a fasting level of 5.6-6.9 $\mathrm{mmol} / \mathrm{l}$ and a $2 \mathrm{hPG}$ level of $7.8-11.09 \mathrm{mmol} / \mathrm{l}$ ). Prediabetes was defined as IFG and/or IGT. Newly diagnosed T2DM was defined by fasting glucose $\geq 7.0 \mathrm{mmol} / \mathrm{l}$ or/and $2 \mathrm{hPG} \geq 11.1 \mathrm{mmol} / \mathrm{l}$ and without known T2DM. Known T2DM was defined by a history of self-reported physician-diagnosed diabetes or glucose-lowering treatment.

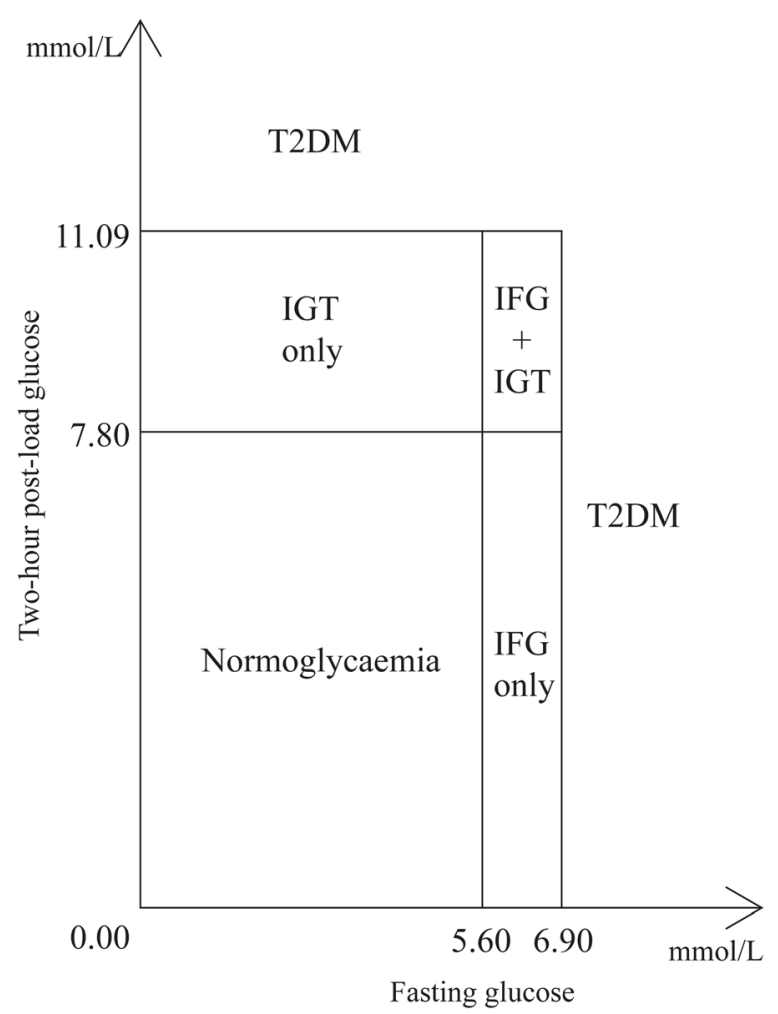

Fig. 1 Classification of glycemic status by fasting glucose and twohour post-load glucose levels. IFG only, impaired fasting glucose only, i.e., fasting level of 5.6-6.9 mmol/l and $2 \mathrm{hPG}<7.8 \mathrm{mmol} / \mathrm{l}$; IGT only, impaired glucose tolerance only, i.e., 2hPG level of 7.8-11.09 $\mathrm{mmol} / \mathrm{l}$ and fasting glucose $<5.6 \mathrm{mmol} / \mathrm{l}, \mathrm{IFG}+\mathrm{IGT}$, the presence of both impaired fasting glucose and impaired glucose tolerance, T2DM type 2 diabetes mellitus, i.e., fasting glucose $\geq 7.0 \mathrm{mmol} / \mathrm{l}$ or $2 \mathrm{hPG} \geq 11.1 \mathrm{mmol} / \mathrm{l} ;$ Known T2DM a history of self-reported physician-diagnosed diabetes or the use of glucose-lowering drugs regularly

\section{Outcomes}

Grip strength was assessed using a Jamar Hydraulic Hand Dynamometer in a standing position. Grip strength of each hand was tested two times and the average value was calculated, expressed as kilograms. The maximal reading of the average grip strength in right and left hands was used as the absolute grip strength (AGS). Measurements of grip strength using Jamar dynamometer showed good to excellent test-retest reproducibility $(r>0.80)$ [29] and excellent $(r=0.98)$ interrater reliability [30]. Maximum relative grip strength (RGS max ) was calculated by AGS divided by BMI. Average relative grip strength (RGS mean) was calculated by the average grip strength in both hands divided by BMI. Relative grip strength in left- or right- hand (RGS left / RGS right) was calculated by the average grip strength in left- or right- hand divided by BMI [31, 32].

\section{Statistical analysis}

Pearson $X^{2}$ test and one-way analysis of variance (ANOVA) were used to compare categorical and continuous variables respectively. The Bonferroni's test was used to control the family-wise error rate. General linear models were used to assess the association of glycemic status and quartiles of fasting glucose in normoglycaemic group with grip strength, giving adjusted regression coefficient $(\beta)$ and $95 \%$ confidence intervals (CIs). We also tested for interaction between sex and glycaemia groups. As significant interactions were observed on the associations with RGS mean and RGS right (P for sex interaction from 0.03 to 0.92 ), all analyses were done on total participants and by sex. Matrix diagram of the measures of grip strength were plotted, with the RGS $\max$ showing the highest correlation coefficient than other measures of grip strength (Supplementary Fig. 1). Thus, we selected RGS max $_{\text {ax }}$ a proxy to investigate the association of fasting glucose and 2hPG with RGS max. Potential confounders were classified as in Table 1. We compared models using different categorizing methods for RGS max including tertiles, quartiles and quintiles in terms of model fitness and found that these three methods showed similar fitness as indicated by the values of Akaike Information Criterion. Hence, to enable comparison with previous studies [21, 33], we categorized RGS max into quintiles. Participants' characteristics

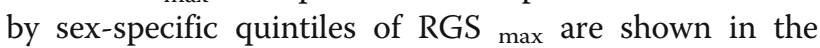
Supplementary Table 1. Statistical analyses were done using Stata version 16.0 (STATA Corp LP, College Station, Texas, USA).

\section{Results}

Table 1 shows that in 2516 men and 6664 women, those with T2DM, versus normoglycaemia, were older and had higher body fat percentage, waist circumference, BMI 
Table 1 Characteristics by diabetes status in 2516 men and 6664 women from the Guangzhou Biobank Cohort Study

\begin{tabular}{|c|c|c|c|c|c|c|c|}
\hline & Normoglycaemia & IFG only & IGT only & IFG + IGT & T2DM & Known T2DM & $P$ value \\
\hline \multicolumn{8}{|l|}{ Men } \\
\hline Number & 1271 & 224 & 363 & 150 & 209 & 299 & \\
\hline Fasting glucose, mmol/l, mean (SD) & $4.93(0.42)$ & $5.93(0.28)$ & $5.08(0.44)$ & $6.01(0.30)$ & $7.09(2.31)$ & $7.70(3.15)$ & $<0.001$ \\
\hline Post-load glucose, mmol/l, mean (SD) & $6.03(1.26)$ & $6.47(1.37)$ & $8.90(0.84)$ & $9.17(0.90)$ & $14.42(4.32)$ & $9.25(4.33)$ & $<0.001$ \\
\hline Age, years, mean (SD) & $67.38(6.68)$ & $67.28(6.71)$ & $69.38(6.49)$ & $68.31(6.68)$ & $69.18(5.66)$ & $68.88(6.37)$ & $<0.001$ \\
\hline \multicolumn{8}{|l|}{ Education, \% } \\
\hline Primary or below & 27.87 & 27.68 & 25.34 & 24.00 & 30.62 & 25.42 & 0.11 \\
\hline Middle school & 57.17 & 52.68 & 57.30 & 58.67 & 52.15 & 51.51 & \\
\hline College or above & 14.96 & 19.64 & 17.36 & 17.33 & 17.22 & 23.08 & \\
\hline \multicolumn{8}{|l|}{ Smoking status, \% } \\
\hline Never & 41.67 & 43.30 & 47.66 & 48.67 & 47.12 & 46.15 & $<0.001$ \\
\hline Former & 24.86 & 29.02 & 29.20 & 30.00 & 30.29 & 31.77 & \\
\hline Current & 33.46 & 27.68 & 23.14 & 21.33 & 22.60 & 22.07 & \\
\hline \multicolumn{8}{|l|}{ Alcohol use, \% } \\
\hline Never & 29.43 & 34.38 & 28.93 & 32.67 & 35.89 & 37.12 & 0.003 \\
\hline Former & 0.63 & 2.68 & 0.00 & 1.33 & 0.48 & 0.67 & \\
\hline Current & 69.94 & 62.95 & 71.07 & 66.00 & 63.64 & 62.21 & \\
\hline \multicolumn{8}{|l|}{ Physical activity, \% } \\
\hline Inactive & 2.28 & 1.34 & 1.38 & 0.67 & 2.87 & 1.34 & 0.24 \\
\hline Minimally active & 27.14 & 25.00 & 30.30 & 24.67 & 34.45 & 28.76 & \\
\hline Active & 70.57 & 73.66 & 68.32 & 74.67 & 62.68 & 69.90 & \\
\hline Poor health, \% & 60.82 & 58.48 & 56.98 & 59.31 & 61.54 & 64.43 & 0.49 \\
\hline Body fat, \%, mean (SD) & $21.04(6.00)$ & $23.35(5.26)$ & $22.47(6.19)$ & $24.47(5.86)$ & $24.47(5.57)$ & $23.01(5.69)$ & $<0.001$ \\
\hline Waist circumference, cm, mean (SD) & $82.30(8.60)$ & $86.35(8.95)$ & $85.18(9.13)$ & $88.07(8.82)$ & $88.17(9.09)$ & $87.20(8.66)$ & $<0.001$ \\
\hline $\mathrm{BMl}, \mathrm{kg} / \mathrm{m}^{2}$, mean (SD) & $22.86(3.08)$ & $23.97(3.32)$ & $23.83(3.46)$ & $25.03(4.34)$ & $24.66(3.20)$ & $24.44(3.47)$ & $<0.001$ \\
\hline \multicolumn{8}{|l|}{ Women } \\
\hline Number & 3395 & 487 & 993 & 391 & 558 & 840 & \\
\hline Fasting glucose, mmol/l, mean (SD) & $4.94(0.36)$ & $5.90(0.27)$ & $5.10(0.36)$ & $6.00(0.32)$ & $6.90(2.14)$ & $7.69(2.85)$ & $<0.001$ \\
\hline Post-load glucose, mmol/l, mean (SD) & $6.14(1.03)$ & $6.67(1.18)$ & $8.91(0.83)$ & $9.19(0.94)$ & $14.28(4.11)$ & $10.98(5.06)$ & $<0.001$ \\
\hline Age, years, mean (SD) & $63.70(6.84)$ & $63.81(7.10)$ & $65.80(6.51)$ & $66.17(6.74)$ & $66.25(6.61)$ & $66.64(6.41)$ & $<0.001$ \\
\hline \multicolumn{8}{|l|}{ Education, \% } \\
\hline Primary or below & 38.47 & 43.33 & 46.83 & 47.83 & 53.23 & 51.90 & $<0.001$ \\
\hline Middle school & 54.46 & 52.77 & 46.02 & 44.76 & 40.32 & 41.07 & \\
\hline College or above & 7.07 & 3.90 & 7.15 & 7.42 & 6.45 & 7.02 & \\
\hline \multicolumn{8}{|l|}{ Smoking status, \% } \\
\hline Never & 97.48 & 97.32 & 97.77 & 98.19 & 97.84 & 97.12 & 0.35 \\
\hline Former & 0.98 & 1.44 & 0.81 & 1.29 & 0.90 & 1.92 & \\
\hline Current & 1.54 & 1.24 & 1.42 & 0.52 & 1.26 & 0.96 & \\
\hline \multicolumn{8}{|l|}{ Alcohol use, \% } \\
\hline Never & 45.71 & 51.85 & 46.27 & 47.06 & 49.01 & 57.23 & $<0.001$ \\
\hline Former & 0.27 & 0.00 & 0.30 & 0.00 & 0.72 & 0.36 & \\
\hline Current & 54.03 & 48.15 & 53.43 & 52.94 & 50.27 & 42.41 & \\
\hline \multicolumn{8}{|l|}{ Physical activity, \% } \\
\hline Inactive & 2.56 & 0.62 & 2.62 & 3.58 & 2.69 & 2.62 & 0.002 \\
\hline
\end{tabular}


Table 1 Characteristics by diabetes status in 2516 men and 6664 women from the Guangzhou Biobank Cohort Study (Continued)

\begin{tabular}{|c|c|c|c|c|c|c|c|}
\hline & Normoglycaemia & IFG only & IGT only & IFG + IGT & T2DM & Known T2DM & $P$ value \\
\hline Minimally active & 21.06 & 20.33 & 23.77 & 23.53 & 24.37 & 27.14 & \\
\hline Active & 76.38 & 79.06 & 73.62 & 72.89 & 72.94 & 70.24 & \\
\hline Poor health, \% & 64.08 & 60.46 & 64.34 & 63.73 & 63.47 & 73.56 & $<0.001$ \\
\hline Body fat, \%, mean (SD) & $31.54(6.74)$ & $34.46(6.74)$ & $33.14(6.71)$ & $36.09(6.56)$ & $36.26(6.66)$ & $33.47(6.69)$ & $<0.001$ \\
\hline Waist circumference, $\mathrm{cm}$, mean (SD) & $79.69(8.40)$ & $82.99(8.71)$ & $82.17(8.57)$ & $84.95(8.68)$ & $85.67(8.95)$ & $83.90(9.27)$ & $<0.001$ \\
\hline BMI, $\mathrm{kg} / \mathrm{m}^{2}$, mean (SD) & $23.30(3.50)$ & $24.47(3.47)$ & $24.19(3.36)$ & $25.19(3.23)$ & $25.53(3.72)$ & $24.48(3.58)$ & $<0.001$ \\
\hline
\end{tabular}

Post-load glucose, $2 \mathrm{~h}$ oral glucose tolerance test; $B M I$ body mass index, $S D$ standard deviation

and lower percentage of current alcohol use ( $P$ from $<$ 0.001 to 0.003$)$. There were also significant differences in physical activity, education and health status in women and smoking status in men with poorer status in T2DM group ( $P$ from $<0.001$ to 0.002 ).

Table 2 shows that, after adjusting for age, education, smoking status, alcohol use, physical activity, body fat percentage and waist circumference, in men, women, and the total participants, RGS max declined from normoglycaemia to prediabetes (from IFG only, to IGT only, then to IFG + IGT), then to known/newly diagnosed T2DM groups ( $P$ for trend $=0.02,0.03$ and 0.005 , respectively). The associations of glycemic stages with grip strength were different in men and women in terms of RGS mean, RGS left, RGS right and AGS. Although the associations of glycemic status with these measures of grip strength (i.e., RGS mean, RGS left, RGS right and AGS) were not statistically significant in women ( $P$ for trend from 0.07 to 0.17 ), significant inverse associations were observed in men ( $P$ for trend from 0.01 to 0.03 ) as well as total participants ( $P$ for trend from 0.005 to 0.03 ).

Table 3 shows that, after similar adjustment, in participants with normoglycaemia, fasting glucose was inversely associated with all measures of RGS and AGS in women ( $P$ for trend from 0.002 to 0.03 ). In women, the adjusted $\beta$ (95\% CI) was $-0.04(-0.08,-0.005)$ for RGS $\max ,-0.04(-0.07,-0.02)$ for RGS mean,-0.05 (-0.08, $-0.02)$ for RGS left, $-0.04(-0.07,-0.006)$ for RGS right and $-0.98(-1.74,-0.22)$ for AGS. However, no association of fasting glucose with grip strength was found in men, when fasting glucose was analyzed as quartiles or continuous ( $P$ for trend from 0.67 to 0.88 ). As the associations did not vary by sex ( $P$ for sex interaction from 0.13 to 0.92 ), we also conducted analysis in total participants and found consistently inverse associations between fasting glucose and all measures of grip strength ( $P$ for trend from 0.006 to 0.049 ). No association between 2hPG and measures of grip strength in normoglycaemic group was found (Supplementary Table 2).

In participants without T2DM, in women, increasing fasting glucose was associated with lower RGS max after full adjustment $(P<0.001$ for trend), with the RGS max
(95\% CI) being $0.88(0.86,0.90)$ in the highest decile and $0.95(0.93,0.97)$ in the lowest. In men, there was similar trend between fasting glucose and RGS max but the association was not statistically significant $(P=0.22)$ (Fig. 2). The association of $2 \mathrm{hPG}$ with RGS max were not significant in both men and women $(P$ value for trend $=0.35$ and 0.39, respectively) (Supplementary Fig. 2).

\section{Discussion}

To our knowledge, this is the first report showing that in women with normoglycaemia, fasting glucose was inversely associated with grip strength in a dose-response manner. In men, glycemic status was inversely associated with grip strength, with a decreasing grip strength from normoglycaemia to prediabetes then to diabetes, but such association was not statistically significant in women, suggesting the inverse association between fasting glucose and grip strength might have begun below the current diagnostic levels for prediabetes or diabetes in women but is more pronounced in men in later stage. Our results indicate an independent contribution of increasing glycaemia within the normal reference range to weaken grip strength, which may shed light on the mechanical functions of muscle strength.

Although some previous studies showed that lower muscle strength was associated with a higher risk of T2DM [20, 26, 34-36], only three studies reported that higher glucose was associated with lower grip strength [12-14]. Results of both directions should be equally important for mechanistic understanding. Our findings were generally consistent with the three previous studies above [12-14] showing that increasing fasting glucose was inversely associated with grip strength. Of these three studies [12-14], the one on 984 participants in the United State (US) showed that raised hemoglobin $\mathrm{A}_{1 \mathrm{c}}$ was associated with decreased muscle strength in the total participants [14], but whether the association varied by sex was not reported. Another study of 1664 participants in the US showed a significant inverse association of fasting glucose with grip strength in men but not in women, and no association between 2hPG and grip strength in men or women [13]. In the study, they only 
Table 2 Grip strength by different diabetes status in 2516 men and 6664 women

\begin{tabular}{|c|c|c|c|c|c|c|c|}
\hline & Normoglycaemia & IFG only & IGT only & IFG + IGT & T2DM & Known T2DM & $\begin{array}{l}P \text { for } \\
\text { trend }\end{array}$ \\
\hline \multicolumn{8}{|l|}{ Men } \\
\hline Number of subjects & 1271 & 224 & 363 & 150 & 209 & 299 & \\
\hline Relative grip strength $\max ^{+}$ & $1.38(1.34,1.42)$ & $1.37(1.33,1.40)$ & $1.36(1.32,1.39)$ & $1.35(1.30,1.39)$ & $1.33(1.29,1.38)$ & $1.32(1.27,1.37)$ & 0.02 \\
\hline Relative grip strength ${ }_{\text {mean }}^{\dagger}$ & $1.30(1.27,1.34)$ & $1.29(1.26,1.33)$ & $1.28(1.25,1.31)$ & $1.27(1.24,1.31)$ & $1.26(1.22,1.30)$ & $1.25(1.21,1.29)$ & 0.01 \\
\hline Relative grip strength left $^{+}$ & $1.30(1.26,1.33)$ & $1.28(1.25,1.32)$ & $1.27(1.23,1.31)$ & $1.26(1.22,1.30)$ & $1.25(1.21,1.29)$ & $1.24(1.19,1.29)$ & 0.01 \\
\hline Relative grip strength right $^{\dagger}$ & $1.31(1.27,1.35)$ & $1.30(1.27,1.33)$ & $1.29(1.26,1.33)$ & $1.28(1.25,1.32)$ & $1.27(1.23,1.31)$ & $1.26(1.22,1.31)$ & 0.01 \\
\hline Absolute grip strength, $\mathrm{kg}^{+\dagger}$ & $32.76(31.88,33.65)$ & $32.52(31.68,33.36)$ & $32.27(31.43,33.12)$ & $32.03(31.14,32.92)$ & $31.79(30.80,32.77)$ & $31.54(30.44,32.64)$ & 0.03 \\
\hline \multicolumn{8}{|l|}{ Women } \\
\hline Number of subjects & 3395 & 487 & 993 & 391 & 558 & 840 & \\
\hline Relative grip strength $\max ^{+}$ & $0.91(0.89,0.92)$ & $0.90(0.89,0.92)$ & $0.90(0.89,0.91)$ & $0.90(0.88,0.91)$ & $0.89(0.87,0.91)$ & $0.88(0.86,0.90)$ & 0.03 \\
\hline Relative grip strength mean $^{\dagger}$ & $0.86(0.84,0.87)$ & $0.85(0.84,0.87)$ & $0.85(0.84,0.86)$ & $0.85(0.84,0.86)$ & $0.85(0.83,0.86)$ & $0.84(0.83,0.86)$ & 0.17 \\
\hline Relative grip strength left $^{\dagger}$ & $0.85(0.84,0.86)$ & $0.85(0.83,0.86)$ & $0.84(0.83,0.86)$ & $0.84(0.83,0.85)$ & $0.84(0.82,0.85)$ & $0.83(0.81,0.85)$ & 0.15 \\
\hline Relative grip strength right $^{\dagger}$ & $0.86(0.85,0.88)$ & $0.86(0.85,0.87)$ & $0.86(0.85,0.87)$ & $0.86(0.84,0.87)$ & $0.85(0.84,0.87)$ & $0.85(0.83,0.87)$ & 0.15 \\
\hline Absolute grip strength, $\mathrm{kg}^{+\dagger}$ & $20.82(20.49,21.14)$ & $20.72(20.43,20.01)$ & $20.62(20.33,20.91)$ & $20.52(20.20,20.85)$ & $20.42(20.04,20.81)$ & $20.33(19.87,20.78)$ & 0.07 \\
\hline \multicolumn{8}{|l|}{ Total } \\
\hline Number of subjects & 4666 & 711 & 1356 & 541 & 767 & 1139 & \\
\hline Relative grip strength $\max ^{\$}$ & $1.02(1.01,1.03)$ & $1.01(1.00,1.02)$ & $1.00(1.00,1.01)$ & $1.00(0.99,1.01)$ & $0.99(0.98,1.00)$ & $0.99(0.97,1.00)$ & 0.005 \\
\hline Relative grip strength mean $\$$ & $0.96(0.95,0.97)$ & $0.95(0.95,0.96)$ & $0.95(0.94,0.96)$ & $0.94(0.94,0.95)$ & $0.94(0.93,0.95)$ & $0.94(0.92,0.95)$ & 0.03 \\
\hline Relative grip strength left $^{\$}$ & $0.95(0.94,0.96)$ & $0.94(0.94,0.95)$ & $0.94(0.93,0.94)$ & $0.93(0.92,0.94)$ & $0.93(0.91,0.94)$ & $0.92(0.91,0.94)$ & 0.02 \\
\hline Relative grip strength right $^{\$}$ & $0.97(0.96,0.98)$ & $0.97(0.96,0.97)$ & $0.96(0.95,0.97)$ & $0.96(0.95,0.97)$ & $0.95(0.94,0.96)$ & $0.95(0.93,0.96)$ & 0.02 \\
\hline Absolute grip strength, $\mathrm{kg}^{\$ \$}$ & $23.79(23.58,24.06)$ & $23.67(23.50,23.84)$ & $23.54(23.38,23.71)$ & $23.42(23.21,23.63)$ & $23.30(23.01,23.58)$ & $23.17(22.81,23.53)$ & 0.008 \\
\hline
\end{tabular}

Results were shown as mean (95\% confidence interval), except for numbers

t: Adjusted for age, education, smoking status, alcohol use, physical activity, body fat percentage and waist circumference

${ }^{++:}$Adjusted for age, education, smoking status, alcohol use, physical activity, body fat percentage and waist circumference and body mass index (BMI)

\$: Adjusted for age, sex, education, smoking status, alcohol use, physical activity, body fat percentage and waist circumference

\$\$: Adjusted for age, sex, education, smoking status, alcohol use, physical activity, body fat percentage and waist circumference and BMI

IFG impaired fasting glucose, IGT impaired glucose tolerance, T2DM type 2 diabetes; relative grip strength max, maximal of the average of the right or the left grip strength divided by BMI; Relative grip strength mean, the mean of the average of both the right and the left grip strength divided by BMl; Relative grip strength ${ }_{\text {left, }}$ the average of the left grip strength divided by $\mathrm{BMI}$; Relative grip strength ${ }_{\text {right, }}$ the average of the right grip strength divided by $\mathrm{BMI}$; Absolute grip strength, maximal of the average of the right or the left grip strength

excluded participants with known diabetes history and those with prediabetes (i.e., IFG and/or IGT) were not excluded from the analysis [13]. However, our study focused on normoglycaemia, which may be the reason for discrepancies between ours and this previous study. In these two studies, in participants without a diagnosis of diabetes, although higher fasting glucose [13] or $\mathrm{HbA}_{1 \mathrm{c}}$ [14] appeared to be associated with lower muscle strength, the results were not statistically significant $[13$, 14]. The other study on 1391 participants from the United Kingdom found that higher 2hPG and the presence of IGT (defined by elevated 2hPG) was associated with lower grip strength in both men and women but no results on the association of fasting glucose or $\mathrm{HbA}_{1 \mathrm{c}}$ with grip strength were reported [12]. Moreover, the above three studies were not large enough and some important confounders were not adjusted in these three studies, such as smoking status [12,13], physical activity [12], body fat percentage [12-14] and waist circumference [12-14]. Hence, our results that fasting glucose was inversely associated with all measures of grip strength in women with normoglycaemia with adjustment for a wide set of potential confounding factors with a large sample size should be more robust, and suggest that association between glycemic metabolism and muscle strength could be causal.

Our results showed that higher fasting glucose, but not $2 \mathrm{hPG}$, was a predictor of lower muscle strength, indicating that fasting glucose might be an earlier glycemic indicator and play a more important role than 2hPG in the mechanism impairing physical function. For individuals with IFG, a previous study showed that insulin resistance was more pronounced in women than that in men [37]. Women generally had higher body fat percentage and thus may be more prone to insulin resistance [38]. However, in those with normoglycaemia, women were shown to be more insulin sensitive than men [39], which may be another explanation for the differences between genders. Our study also showed that in participants without a diagnosis of diabetes, the inverse association between glycaemia and grip strength was significant in women 
Table 3 Grip strength by fasting glucose (in quartiles and as continuous, mmol/l) in 1271 men and 3394 women with normoglycaemia

\begin{tabular}{|c|c|c|c|c|c|c|}
\hline & \multicolumn{4}{|c|}{ Quartile of fasting glucose in normoglycaemia, $\mathrm{mmol} / \mathrm{l}$} & \multirow[t]{2}{*}{ Adjusted $\beta^{+}$} & \multirow{2}{*}{$\begin{array}{l}P \text { for } \\
\text { trend }\end{array}$} \\
\hline & $\overline{1 s t}$ & 2nd & 3rd & 4th & & \\
\hline \multicolumn{7}{|l|}{ Men } \\
\hline Number of subjects & 314 & 310 & 319 & 328 & - & - \\
\hline Fasting glucose, mmol/l & $4.39(4.35,4.42)$ & $4.82(4.81,4.83)$ & $5.07(5.07,5.08)$ & $5.40(5.38,5.42)$ & - & - \\
\hline Post-load glucose, $\mathrm{mmol} / \mathrm{l}^{\dagger}$ & $5.94(5.76,6.13)$ & $6.14(5.97,6.30)$ & $6.26(6.10,6.43)$ & $6.42(6.24,6.60)$ & $0.51(0.33,0.68)^{* * *}$ & $<0.001$ \\
\hline Relative grip strength $\max ^{+}$ & $1.43(1.37,1.49)$ & $1.43(1.37,1.48)$ & $1.43(1.37,1.48)$ & $1.43(1.37,1.49)$ & $-0.004(-0.06,0.05)$ & 0.88 \\
\hline Relative grip strength mean $^{\dagger}$ & $1.35(1.30,1.41)$ & $1.35(1.30,1.40)$ & $1.35(1.30,1.39)$ & $1.35(1.30,1.40)$ & $-0.01(-0.06,0.04)$ & 0.70 \\
\hline Relative grip strength left ${ }^{\dagger}$ & $1.35(1.29,1.41)$ & $1.34(1.29,1.40)$ & $1.34(1.28,1.40)$ & $1.34(1.28,1.40)$ & $-0.01(-0.07,0.05)$ & 0.67 \\
\hline Relative grip strength right $^{+}$ & $1.36(1.31,1.41)$ & $1.36(1.31,1.40)$ & $1.36(1.31,1.40)$ & $1.35(1.31,1.40)$ & $-0.008(-0.05,0.04)$ & 0.75 \\
\hline Absolute grip strength, $\mathrm{kg}^{\dagger \dagger}$ & $33.27(31.92,34.61)$ & $33.21(32.03,34.40)$ & $33.18(32.00,34.36)$ & $33.14(31.85,34.42)$ & $-0.14(-1.39,1.12)$ & 0.83 \\
\hline \multicolumn{7}{|l|}{ Women } \\
\hline Number of subjects & 840 & 833 & 844 & 877 & - & - \\
\hline Fasting glucose, mmol/l & $4.46(4.45,4.48)$ & $4.82(4.82,4.82)$ & $5.07(5.07,5.08)$ & $5.37(5.37,5.38)$ & - & - \\
\hline Post-load glucose, $\mathrm{mmol} / \mathrm{l}^{\dagger}$ & $5.89(5.82,5.97)$ & $6.07(6.01,6.13)$ & $6.19(6.13,6.25)$ & $6.34(6.26,6.41)$ & $0.47(0.37,0.57)^{* * *}$ & $<0.001$ \\
\hline Relative grip strength $\max ^{\dagger}$ & $0.95(0.93,0.98)$ & $0.94(0.92,0.96)$ & $0.93(0.91,0.95)$ & $0.92(0.89,0.94)$ & $-0.04(-0.08,-0.005)^{*}$ & 0.03 \\
\hline Relative grip strength mean $^{+}$ & $0.90(0.88,0.92)$ & $0.89(0.87,0.90)$ & $0.87(0.86,0.89)$ & $0.86(0.84,0.88)$ & $-0.04(-0.07,-0.02)^{* *}$ & 0.002 \\
\hline Relative grip strength left $^{\dagger}$ & $0.90(0.87,0.92)$ & $0.88(0.86,0.90)$ & $0.87(0.85,0.89)$ & $0.85(0.83,0.88)$ & $-0.05(-0.08,-0.02)^{* *}$ & 0.003 \\
\hline Relative grip strength right $^{\dagger}$ & $0.91(0.88,0.93)$ & $0.89(0.87,0.91)$ & $0.88(0.86,0.90)$ & $0.87(0.85,0.89)$ & $-0.04(-0.07,-0.006)^{*}$ & 0.02 \\
\hline Absolute grip strength, $\mathrm{kg}^{\dagger \dagger}$ & $21.26(20.70,21.83)$ & $20.89(20.45,21.33)$ & $20.64(20.19,21.10)$ & $20.34(19.77,20.90)$ & $-0.98(-1.74,-0.22)^{*}$ & 0.01 \\
\hline \multicolumn{7}{|l|}{ Total } \\
\hline Number of subjects & 1154 & 1143 & 1163 & 1205 & & \\
\hline Fasting glucose, mmol/l & $4.44(4.43,4.46)$ & $4.82(4.816,4.82)$ & $5.07(5.07,5.08)$ & $5.38(5.37,5.39)$ & - & - \\
\hline Post-load glucose, $\mathrm{mmol} / \mathrm{l}^{\$}$ & $5.88(5.82,5.93)$ & $6.06(6.03,6.09)$ & $6.18(6.15,6.22)$ & $6.33(6.28,6.38)$ & $0.48(0.40,0.57)^{* * *}$ & $<0.001$ \\
\hline Relative grip strength $\max ^{\$}$ & $1.06(1.04,1.08)$ & $1.05(1.04,1.06)$ & $1.04(1.03,1.06)$ & $1.03(1.02,1.05)$ & $-0.03(-0.06,-0.00008)^{*}$ & 0.049 \\
\hline Relative grip strength mean $\$$ & $1.01(0.99,1.02)$ & $0.99(0.98,1.00)$ & $0.98(0.97,0.99)$ & $0.97(0.96,0.99)$ & $-0.04(-0.06,-0.01)^{* *}$ & 0.006 \\
\hline Relative grip strength left $\$$ & $1.00(0.98,1.01)$ & $0.98(0.97,0.99)$ & $0.97(0.96,0.98)$ & $0.96(0.94,0.98)$ & $-0.04(-0.07,-0.01)^{* *}$ & 0.008 \\
\hline Relative grip strength right $\$$ & $1.01(1.00,1.03)$ & $1.00(0.99,1.01)$ & $1.00(0.99,1.01)$ & $0.99(0.97,1.00)$ & $-0.03(-0.06,-0.003)^{*}$ & 0.03 \\
\hline Absolute grip strength, $\mathrm{kg}^{\$ \$}$ & $24.23(23.82,24.63)$ & $23.97(23.72,24.22)$ & $23.80(23.54,24.06)$ & $23.59(23.21,23.97)$ & $-0.68(-1.33,-0.02)^{*}$ & 0.04 \\
\hline
\end{tabular}

Results were shown as mean (95\% confidence interval), except for numbers

Relative grip strength max, maximal of the average of the right or the left grip strength divided by body mass index (BMI); Relative grip strength mean the mean of the average of both the right and the left grip strength divided by BMl; Relative grip strength left, the average of the left grip strength divided by BMl; Relative grip strength ${ }_{\text {right, }}$ the average of the right grip strength divided by BMI; Absolute grip strength, maximal of the average of the right or the left grip strength $P$ values for sex interaction with fasting glucose in terms of all measures of grip strength were from 0.13 to 0.92

${ }^{\dagger}:$ Adjusted for age, education, smoking status, alcohol use, physical activity, body fat percentage and waist circumference

${ }^{+\dagger}$ : Adjusted for age, education, smoking status, alcohol use, physical activity, body fat percentage and waist circumference and BMI

\$: Adjusted for age, sex, education, smoking status, alcohol use, physical activity, body fat percentage and waist circumference

$\$ \$$ : Adjusted for age, sex, education, smoking status, alcohol use, physical activity, body fat percentage and waist circumference and BMI

*: $P<0.05 ;{ }^{* *}: P<0.01 ;{ }^{* * *}: P<0.001$

Note: IFG impaired fasting glucose, IGT impaired glucose tolerance, T2DM type 2 diabetes mellitus

but not in men. Moreover, our results were also consistent with an experimental study of animals showing that contractile function and force generation were affected by hyperglycemia [40]. Furthermore, as all analyses on grip strength had accounted for BMI, the different associations in men and women were unlikely due to the changes in BMI caused by hyperglycemia. Some explanations for the mechanisms of glucose metabolism and grip strength have been postulated. First, insulin resistance, which is a key underlying metabolic abnormality in hyperglycemia, may induce muscle degradation via the pathways of activation of caspase- 3 and the ubiquitin-proteasome proteolytic [41]. Second, elevating fasting glucose is associated with glycogenolysis [42], which may partly contribute to the loss of muscle strength. Third, hyperglycemia may lead to a lower muscle strength through effects on skeletal muscle mitochondria. An 


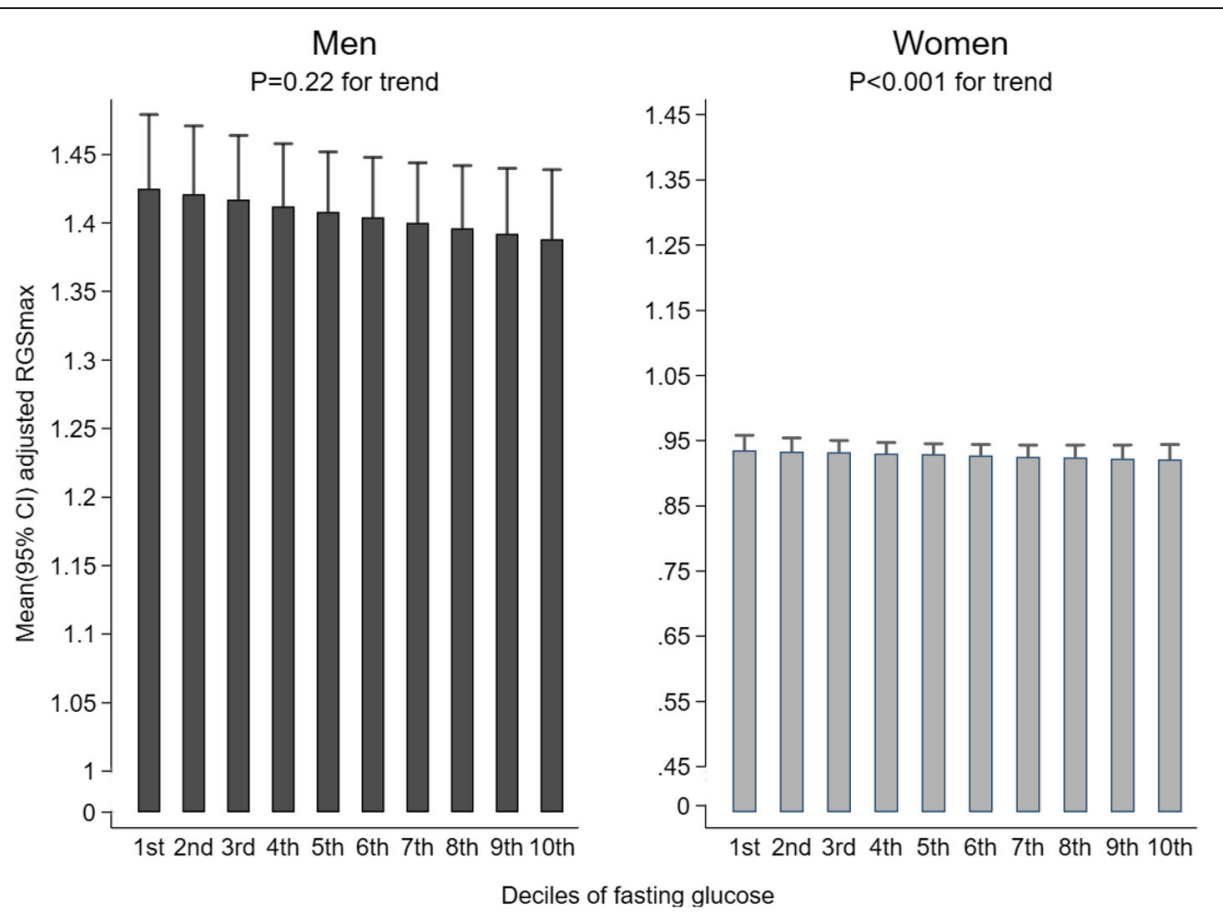

Fig. 2 Association between fasting glucose (in deciles and as continuous, mmol/l) and RGS max in participants without T2DM. All the means (95\% CIs) were adjusted for age, education, smoking status, alcohol use, physical activity, body fat percentage and waist circumference. Note: $r=$ correlation coefficient

impaired bioenergetic capacity dysfunction of muscle mitochondria was found in patients with type 2 diabetes, and higher insulin resistance was associated with more severe damage in mitochondria [43]. Forth, hyperglycemia may lead to a decline in muscle strength via krüppel-like factor 15 protein [44], which has been found to regulate skeletal muscle lipid flux as well as exercise adaptation [45]. Finally, individuals with hyperglycemia were found to have higher levels of inflammatory cytokines such as interleukin- 6 and tumor necrosis factoralpha $[46,47]$ and these inflammatory factors may also have some adverse effects on muscle mass [48, 49].

The strengths of our study included the large sample size, standardized and comprehensive measurement of anthropometric parameters (body fat percentage, waist circumference and BMI), glycaemia (fasting glucose and 2hPG) and grip strength. However, our study had several limitations. First, as the associations were cross-sectional, whether the association between glycemic status and grip strength is causal is uncertain. Second, there are some factors that may influence the instantaneous strength tests and thus residual confounding could not be completely ruled out, although a wide range of potential confounding factors were adjusted for and the results remained after the adjustment. Third, as all participants were older people who might have relatively lower grip strength, the results may not be applicable to other age groups.

\section{Conclusions}

In conclusion, higher fasting glucose was associated with reduced grip strength in a dose-response manner in men from normoglycaemia to prediabetes then to T2DM, and the association was significant even in women with normoglycaemia. Our findings suggest that lowering glucose across the whole range might be important in preserving muscle strength, especially in aging women. Further studies on the mechanisms and trials are warranted.

\section{Supplementary information}

Supplementary information accompanies this paper at https://doi.org/10. 1186/s12877-020-01808-0.

Additional file 1. Supplementary Table 1. Characteristics by quintiles of relative grip strength max in 2498 men and 6638 women in Guangzhou Biobank Cohort Study. SD = standard deviation; Relative grip strength max, maximal of the average of the right or the left grip strength divided by body mass index (BMI)

Additional file $\mathbf{2}$ Supplementary Table 2. Grip strength by post-load glucose (in quartiles and as continuous, mmol/l) in 1178 men and 3080 women with normoglycaemia. Results were shown as mean (95\% 
confidence interval), except for numbers. Relative grip strength max, maximal of the average of the right or the left grip strength divided by body mass index (BMI); Relative grip strength mean, the mean of the average of both the right and the left grip strength divided by BMI; Relative grip strength left, the average of the left grip strength divided by BMl; Relative grip strength ${ }_{\text {right, }}$ the average of the right grip strength divided by $\mathrm{BMl}$; Absolute grip strength, maximal of the average of the right or the left grip strength. ${ }^{\dagger}$ : Adjusted for age, education, smoking status, alcohol use, physical activity, body fat percentage and waist circumference. ${ }^{+t}$ : Adjusted for age, education, smoking status, alcohol use, physical activity, body fat percentage and waist circumference and BMI. \$: Adjusted for age, sex, education, smoking status, alcohol use, physical activity, body fat percentage and waist circumference. ${ }^{\$ \$}$ : Adjusted for age, sex, education, smoking status, alcohol use, physical activity, body fat percentage and waist circumference and BMI. \#: $P$ value for sex interaction with post-load glucose in terms of relative grip strength mean and relative grip strength right was 0.04 and 0.03 respectively. ${ }^{* *}: P<0.01 ;{ }^{* *}: P<0.001$

Additional file 3. Supplementary Figure 1. The matrix diagram of the measures of grip strength

Additional file 4. Supplementary Figure 2. Association between 2hPG (in deciles and as continuous, $\mathrm{mmol} / \mathrm{l}$ ) and RGS max in participants without T2DM. All the means ( $95 \% \mathrm{Cls}$ ) were adjusted for age, education, smoking status, alcohol use, physical activity, body fat percentage and waist circumference

\section{Abbreviations}

RGS: Relative grip strength; DM: Diabetes mellitus; T2DM: Type 2 diabetes mellitus; 2hPG: 2-h post-load glucose; GBCS: Guangzhou Biobank Cohort Study; GHHARE: Guangzhou Health and Happiness Association for the Respectable Elders); BMI: Body mass index; IFG: Impaired fasting glucose; IGT: Impaired glucose tolerance; IFG + IGT: IFG and IGT; AGS: Absolute grip strength; RGS: max Relative grip strength maxi RGS: mean Relative grip strength meani RGS: left Relative grip strength lefti RGS: rightRelative grip strength right

\section{Acknowledgements}

Not Applicable.

\section{Authors' contributions}

$X L, L X, T H L, W S Z, F Z, Y L J, C Q J$ and KKC have substantial contributions to conception and design, acquisition of funding, data and interpretation of data; YYH, LX, CQJ and THL analyzed the data; YYH, LX, CQJ, THL and KKC drafted the article; LX, CQJ, THL and KKC revised it critically for important intellectual content. All authors read and approved the final manuscript.

\section{Funding}

The Guangzhou Biobank Cohort Study investigators include: Guangzhou No. 12 Hospital: WS Zhang, M Cao, T Zhu, B Liu, CQ Jiang (Co-principal investigator (PI)); The University of Hong Kong: CM School, SM McGhee, GM Leung, R Fielding, TH Lam (Co-PI); The University of Birmingham: P Adab, GN Thomas, KK Cheng (Co-PI). This work was funded by the National Key R\&D Program of China (2017YFC0907100), Natural Science Foundation of Guangdong (2018A030313140), the Natural Science Foundation of China (No. 81941019), the Guangzhou Science and Technology Bureau (201704030132), the Major Infectious Disease Prevention and Control of the National Science and Technique Major Project (2018ZX10715004) and the University of Birmingham, UK. The funding body has no contributions to the design of the study and collection, analysis, and interpretation of data and in writing the manuscript.

\section{Availability of data and materials}

The datasets used during the current study are available from the corresponding author on reasonable request.

\section{Ethics approval and consent to participate}

Our study was approved by the Guangzhou Medical Ethics Committee of the Chinese Medical Association. All participants provided written informed consent before participation in the GBCS.

\section{Consent for publication}

Not applicable.

\section{Competing interests}

The authors declare that they have no competing interests.

\section{Author details}

${ }^{1}$ School of Public Health, Sun Yat-sen University, Guangzhou, China. ${ }^{2}$ Guangzhou No.12 Hospital, Guangzhou 510620, China. ${ }^{3}$ Institute of Applied Health Research, University of Birmingham, Birmingham, UK. ${ }^{4}$ School of Public Health, the University of Hong Kong, Hong Kong, China.

\section{Received: 28 July 2020 Accepted: 30 September 2020}

Published online: 12 October 2020

\section{References}

1. Fried LP, Tangen CM, Walston J, Newman AB, Hirsch C, Gottdiener J, Seeman T, Tracy R, Kop WJ, Burke G, et al. Frailty in older adults: evidence for a phenotype. J Gerontol A Biol Sci Med Sci. 2001;56(3):M146-56.

2. Ottenbacher KJ, Graham JE, Al Snih S, Raji M, Samper-Ternent R, Ostir GV, Markides KS. Mexican Americans and frailty: findings from the Hispanic established populations epidemiologic studies of the elderly. Am J Public Health. 2009;99(4):673-9.

3. Visser M, Schaap LA. Consequences of sarcopenia. Clin Geriatr Med. 2011; 27(3):387-99.

4. Sayer AA, Kirkwood TBL. Grip strength and mortality: a biomarker of ageing? Lancet (London, Engl). 2015;386(9990):226-7.

5. Bohannon RW. Muscle strength: clinical and prognostic value of hand-grip dynamometry. Curr Opin Clin Nutr Metab Care. 2015;18(5):465-70.

6. Porto JM, Nakaishi APM, Cangussu-Oliveira LM, Freire Júnior RC, Spilla SB, DCCd A. Relationship between grip strength and global muscle strength in community-dwelling older people. Arch Gerontol Geriatr. 2019;82:273-8.

7. International Diabetes Federation (IDF) Diabetes atlas $9^{\text {th }}$ edition. 2019.

8. Yang SH, Dou KF, Song WJ. Prevalence of diabetes among men and women in China. N Engl J Med. 2010;362(25):2425-6.

9. Xu Y, Wang $L$, He J, Bi Y, Li M, Wang T, Wang L, Jiang Y, Dai M, Lu J, et al. Prevalence and control of diabetes in Chinese adults. JAMA. 2013;310(9): 948-59.

10. Åström MJ, von Bonsdorff MB, Perälä MM, Salonen MK, Rantanen T, Kajantie E, Simonen M, Pohjolainen P, Osmond C, Eriksson JG. Glucose regulation and physical performance among older people: the Helsinki birth cohort study. Acta Diabetol. 2018;55(10):1051-8.

11. Wong E, Backholer K, Gearon E, Harding J, Freak-Poli R, Stevenson C, Peeters A. Diabetes and risk of physical disability in adults: a systematic review and meta-analysis. Lancet Diabetes Endocrinol. 2013;1(2):106-14.

12. Sayer AA, Dennison EM, Syddall HE, Gilbody HJ, Phillips DIW, Cooper C. Type 2 diabetes, muscle strength, and impaired physical function: the tip of the iceberg? Diabetes Care. 2005;28(10):2541-2.

13. Kalyani RR, Kim C, Ferrucci L, Laughlin GA, Kritz-Silverstein D, Kong S, Nan B, Barrett-Connor E. Sex differences in the association of fasting and postchallenge glucose levels with grip strength among older adults: the rancho Bernardo study. BMJ Open Diabetes Res Care. 2015;3(1):e000086.

14. Kalyani RR, Metter EJ, Egan J, Golden SH, Ferrucci L. Hyperglycemia predicts persistently lower muscle strength with aging. Diabetes Care. 2015;38(1):82-90.

15. Jiang C, Thomas GN, Lam TH, Schooling CM, Zhang W, Lao X, Adab P, Liu B, Leung GM, Cheng KK. Cohort profile: the Guangzhou biobank cohort study, a Guangzhou-Hong Kong-Birmingham collaboration. Int J Epidemiol. 2006; 35(4):844-52.

16. Reynolds K, Gu D, Muntner P, Wu X, Chen J, Huang G, Duan X, Whelton PK, He J. Geographic variations in the prevalence, awareness, treatment and control of hypertension in China. J Hypertens. 2003;21(7):1273-81.

17. Gu D, Reynolds K, Duan X, Xin X, Chen J, Wu X, Mo J, Whelton PK, He J. Prevalence of diabetes and impaired fasting glucose in the Chinese adult population: international collaborative study of cardiovascular disease in Asia (InterASIA). Diabetologia. 2003;46(9):1190-8.

18. Xu L, Jiang CQ, Lam TH, Zhang WS, Thomas GN, Cheng KK. Dose-response relation between physical activity and cognitive function: Guangzhou biobank cohort study. Ann Epidemiol. 2011;21(11):857-63.

19. Clark BC, Manini TM. What is dynapenia? Nutrition (Burbank, Los Angeles County, Calif). 2012;28(5):495-503.

20. Lee MR, Jung SM, Bang H, Kim HS, Kim YB. Association between muscle strength and type 2 diabetes mellitus in adults in Korea: Data from the Korea national health and nutrition examination survey (KNHANES) Vl. Medicine (Baltimore). 2018;97(23):e10984. 
21. Strand BH, Cooper R, Bergland A, Jorgensen L, Schirmer H, Skirbekk V, Emaus $\mathrm{N}$. The association of grip strength from midlife onwards with allcause and cause-specific mortality over 17 years of follow-up in the Tromso study. J Epidemiol Commun Health. 2016;70(12):1214-21.

22. Buchmann N, Spira D, Konig M, Norman K, Demuth I, Steinhagen-Thiessen E. Problematic drinking in the old and its association with muscle mass and muscle function in type II diabetes. Sci Rep. 2019;9(1):12005.

23. Celis-Morales CA, Lyall DM, Anderson J, Iliodromiti S, Fan Y, Ntuk UE, Mackay DF, Pell JP, Sattar N, Gill JM. The association between physical activity and risk of mortality is modulated by grip strength and cardiorespiratory fitness: evidence from 498135 UK-biobank participants. Eur Heart J. 2017;38(2):116-22.

24. Park SW, Goodpaster BH, Strotmeyer ES, de Rekeneire N, Harris TB, Schwartz $A V$, Tylavsky FA, Newman AB. Decreased muscle strength and quality in older adults with type 2 diabetes: the health, aging, and body composition study. Diabetes. 2006;55(6):1813-8.

25. Kawamoto R, Ninomiya D, Kasai Y, Kusunoki T, Ohtsuka N, Kumagi T, Abe M. Handgrip strength is associated with metabolic syndrome among middleaged and elderly community-dwelling persons. Clin Exp Hypertens. 2016; 38(2):245-51.

26. Wander PL, Boyko EJ, Leonetti DL, McNeely MJ, Kahn SE, Fujimoto WY. Greater hand-grip strength predicts a lower risk of developing type 2 diabetes over 10 years in leaner Japanese Americans. Diabetes Res Clin Pract. 2011;92(2):261-4.

27. Jiang $C Q, X u L$, Lam TH, Jin YL, Sen Zhang W, Zhu F, Thomas GN, Cheng KK. Glycemic Measures and Risk of Mortality in Older Chinese: The Guangzhou Biobank Cohort Study. J Clin Endocrinol Metab. 2020;105(3).

28. American Diabetes A. Diagnosis and classification of diabetes mellitus. Diabetes Care. 2014;37(Suppl 1):\$81-90.

29. Mathiowetz V, Weber K, Volland G, Kashman N. Reliability and validity of grip and pinch strength evaluations. J Hand Surg. 1984;9(2):222-6.

30. Peolsson A, Hedlund R, Oberg B. Intra- and inter-tester reliability and reference values for hand strength. J Rehabil Med. 2001;33(1):36-41.

31. Lawman HG, Troiano RP, Perna FM, Wang CY, Fryar CD, Ogden CL. Associations of relative handgrip strength and cardiovascular disease biomarkers in U.S. adults, 2011-2012. Am J Prev Med. 2016;50(6):677-83.

32. Hansen D, Niebauer J, Cornelissen V, Barna O, Neunhauserer D, Stettler C, Tonoli C, Greco E, Fagard R, Coninx K, et al. Exercise Prescription in Patients with Different Combinations of Cardiovascular Disease Risk Factors: A Consensus Statement from the EXPERT Working Group. Sports Med (Auckland, NZ). 2018;48(8):1781-97.

33. Farmer RE, Mathur R, Schmidt AF, Bhaskaran K, Fatemifar G, Eastwood SV, Finan C, Denaxas S, Smeeth L, Chaturvedi N. Associations between measures of Sarcopenic obesity and risk of cardiovascular disease and mortality: a cohort study and Mendelian randomization analysis using the UK biobank. J Am Heart Assoc. 2019;8(13):e011638.

34. Yeung CHC, Au Yeung SL, Fong SSM, Schooling CM. Lean mass, grip strength and risk of type 2 diabetes: a bi-directional Mendelian randomisation study. Diabetologia. 2019;62(5):789-99.

35. Tarp J, Stole AP, Blond K, Grontved A. Cardiorespiratory fitness, muscular strength and risk of type 2 diabetes: a systematic review and meta-analysis. Diabetologia. 2019;62(7):1129-42.

36. Martinus R, Corban R, Wackerhage $H$, Atkins S, Singh J. Effect of psychological intervention on exercise adherence in type 2 diabetic subjects. Ann N Y Acad Sci. 2006:1084:350-60.

37. Hanefeld M, Koehler C, Fuecker K, Henkel E, Schaper F, TemelkovaKurktschiev T. Insulin secretion and insulin sensitivity pattern is different in isolated impaired glucose tolerance and impaired fasting glucose: the risk factor in impaired glucose tolerance for atherosclerosis and Diabetes study. Diabetes Care. 2003;26(3):868-74.

38. Patel $\mathrm{P}$, Abate $\mathrm{N}$ : Role of subcutaneous adipose tissue in the pathogenesis of insulin resistance. J Obes 2013, 2013:489187.

39. Chan Z, Chooi YC, Ding C, Choo J, Sadananthan SA, Michael N, Velan SS, Leow MK, Magkos F. Sex differences in glucose and fatty acid metabolism in Asians who are nonobese. J Clin Endocrinol Metab. 2019;104(1):127-36.

40. Helander I, Westerblad $\mathrm{H}$, Katz A. Effects of glucose on contractile function [Ca2+]i, and glycogen in isolated mouse skeletal muscle. Am J Physiol Cell Physiol. 2002;282(6):C1306-12.

41. Wang $X, \mathrm{Hu} Z, \mathrm{Hu} J, \mathrm{Du} J$, Mitch WE. Insulin resistance accelerates muscle protein degradation: activation of the ubiquitin-proteasome pathway by defects in muscle cell signaling. Endocrinology. 2006;147(9):4160-8.
42. Basu R, Barosa C, Jones J, Dube S, Carter R, Basu A, Rizza RA. Pathogenesis of prediabetes: role of the liver in isolated fasting hyperglycemia and combined fasting and postprandial hyperglycemia. J Clin Endocrinol Metab. 2013;98(3):E409-17.

43. Kelley DE, He J, Menshikova EV, Ritov VB. Dysfunction of mitochondria in human skeletal muscle in type 2 diabetes. Diabetes. 2002;51(10):2944-50.

44. Hirata Y, Nomura K, Senga Y, Okada Y, Kobayashi K, Okamoto S, Minokoshi Y, Imamura M, Si T, Hosooka T, et al. Hyperglycemia induces skeletal muscle atrophy via a WWP1/KLF15 axis. JCI Insight. 2019;4(4):e124952.

45. Haldar SM, Jeyaraj D, Anand P, Zhu H, Lu Y, Prosdocimo DA, Eapen B, Kawanami D, Okutsu M, Brotto L, et al. Kruppel-like factor 15 regulates skeletal muscle lipid flux and exercise adaptation. Proc Natl Acad Sci U S A. 2012;109(17):6739-44.

46. Park SW, Goodpaster BH, Strotmeyer ES, Kuller LH, Broudeau R, Kammerer C, de Rekeneire N, Harris TB, Schwartz AV, Tylavsky FA, et al. Accelerated loss of skeletal muscle strength in older adults with type 2 diabetes: the health, aging, and body composition study. Diabetes Care. 2007;30(6):1507-12.

47. Bianchi L, Zuliani G, Volpato S. Physical disability in the elderly with diabetes: epidemiology and mechanisms. Curr Diab Rep. 2013;13(6):824-30.

48. Schaap LA, Pluijm SM, Deeg DJ, Visser M. Inflammatory markers and loss of muscle mass (sarcopenia) and strength. Am J Med. 2006;119(6): 526 e529-517.

49. Visser M, Pahor M, Taaffe DR, Goodpaster BH, Simonsick EM, Newman AB, Nevitt M, Harris TB. Relationship of interleukin-6 and tumor necrosis factoralpha with muscle mass and muscle strength in elderly men and women: the health ABC study. J Gerontol A Biol Sci Med Sci. 2002;57(5):M326-32.

\section{Publisher's Note}

Springer Nature remains neutral with regard to jurisdictional claims in published maps and institutional affiliations.

\section{Ready to submit your research? Choose BMC and benefit from:}

- fast, convenient online submission

- thorough peer review by experienced researchers in your field

- rapid publication on acceptance

- support for research data, including large and complex data types

- gold Open Access which fosters wider collaboration and increased citations

- maximum visibility for your research: over $100 \mathrm{M}$ website views per year

At BMC, research is always in progress.

Learn more biomedcentral.com/submissions 